\title{
Synovial T cell hyporesponsiveness to myeloid dendritic cells is reversed by preventing PD-1/ PD-L1 interactions
}

Frederique M Moret ${ }^{1,2^{*}}$, Kim MG van der Wurff-Jacobs' ${ }^{1}$, Johannes WJ Bijlsma' ${ }^{1}$, Floris PJG Lafeber ${ }^{1}$ and Joel AG van Roon ${ }^{1,2^{*}}$

\begin{abstract}
Introduction: The aim of this study was to investigate PD-1/PD-L1 involvement in the hyporesponsiveness of rheumatoid arthritis (RA) synovial fluid (SF) CD4 T cells upon stimulation by thymic stromal lymphopoietin (TSLP)-primed CD1c myeloid dendritic cells (mDCs).

Methods: Expression of PD-1 on naïve (Tn), central memory $(T \mathrm{~cm})$ and effector memory (Tem) CD4 T cell subsets was assessed by flow cytometry. PD-L1 expression and its regulation upon TSLP stimulation of mDCs from peripheral blood (PB) and SF of RA patients were investigated by quantitative RT-PCR and flow cytometry. The involvement of PD-1/PD-L1 interactions in SF T cell hyporesponsiveness upon (TSLP-primed) mDC activation was determined by cell culture in the presence of PD-1 blocking antibodies, with or without interleukin 7 (IL-7) as a recognized suppressor of PD-1 expression.

Results: PD-1 expression was increased on CD4 T cells derived from SF compared with PB of RA patients. TSLP increased PD-L1 mRNA expression in both PB and SF mDCs. PD-L1 protein expression was increased on SF mDCs compared with PB mDCs and was associated with T cell hyporesponsiveness. Blockade of PD-1, as well as IL-7 stimulation, during cocultures of memory T cells and (TSLP-primed) mDCs from RA patients significantly recovered $T$ cell proliferation.

Conclusion: SF T cell hyporesponsiveness upon (TSLP-primed) mDC stimulation in RA joints is partially dependent on PD-1/PD-L1 interactions, as PD-1 and PD-L1 are both highly expressed on SF T cells and mDCs, respectively, and inhibiting PD-1 availability restores T cell proliferation. The potential of IL-7 to robustly reverse this hyporesponsiveness suggests that such proinflammatory cytokines in RA joints strongly contribute to memory T cell activation.
\end{abstract}

\section{Introduction}

Rheumatoid arthritis (RA) is characterised by progressive joint inflammation that results in tissue damage [1]. This is strongly dependent on CD4 T cell production of Th1 (interferon $\gamma$ ) and Th17 cytokines (interleukin 17 (IL-17)) [2-5]. Activation and differentiation of CD4 T cells to become Th1 or Th17 cells is strongly regulated by antigenpresenting cells such as dendritic cells (DCs) [6]. Several types of DCs are known to circulate in human blood. They are characterised by high expression of human leucocyte

\footnotetext{
* Correspondence: f.m.moret@umcutrecht.nl; j.vanroon@umcutrecht.nl 'Department of Rheumatology \& Clinical Immunology, University Medical Center Utrecht, PO Box 85500, 3508 GA Utrecht, The Netherlands

${ }^{2}$ Laboratory of Translational Immunology, University Medical Center Utrecht, PO Box 85090, 3508 AB Utrecht, The Netherlands
}

antigen (HLA) class II molecules and the absence of lineage markers (CD3, CD19, CD14, CD20, CD56 and glycophorin A). Human blood DCs can be divided into at least three subtypes (plasmacytoid DCs and two types of myeloid or classical DCs ( $\mathrm{mDC} 1$ and $\mathrm{mDC} 2)$ ) $[7,8]$, based on the blood-derived DC antigen (BDCA) molecules $[9,10]$. BDCA-1 (CD1c) identifies the $\mathrm{mDC1}$ subset, which comprises potent activators of CD4 $\mathrm{T}$ cells, whereas mDC2 cells, identified by expression of BDCA-3 (CD141), more potently activate CD8 T cells $[7,9,10]$. In this respect, it is important to note that the characterisation of $\mathrm{mDC} 1$ cells by CD1c is more specific than the previously used and more broadly expressed marker, CD11c [7,9]. CD1c $\mathrm{mDCs}$ are abundantly present in joints of RA patients, and these synovial fluid (SF)-derived $\mathrm{mDCs}$ have recently 
been demonstrated to have an extremely strong capacity to activate autologous peripheral blood (PB)-derived CD4 T cells [11].

Thymic stromal lymphopoietin (TSLP) has recently been considered as a potential trigger to activate CD1c mDCs in the joints of RA patients. TSLP cytokine levels are significantly increased in the SF of RA patients compared with SF of osteoarthritis patients [12,13]. TSLP has been demonstrated to potently activate TSLPR-expressing CD1c mDCs from SF to secrete enhanced levels of T cellattracting chemokines and to strongly activate PB-derived CD4 T cells to induce Th1, Th17 and Th2 activity [13]. In addition, recently, TSLP and its receptor were also shown to enhance Th1- and Th17-mediated experimental arthritis and tissue destruction [14].

Because of the prominent role of CD4 $\mathrm{T}$ cells in arthritic processes and the potential of SF-derived $\mathrm{mDCs}$ and TSLP-primed mDCs to activate autologous PBderived CD4 T cells, in this study we investigated the potential of these mDCs to activate autologous SF-derived CD4 $\mathrm{T}$ cells. An evident hyporesponsiveness of SFderived CD4 T cells upon $\mathrm{mDC}$ or TSLP-primed $\mathrm{mDC}$ activation was observed. Several observations led us to investigate the role of programmed death 1 (PD-1) and its ligand interactions in this hyporesponsiveness, because ligation of PD-1 by PD-L1 or PD-L2 leads to inhibition of $\mathrm{T}$ cell proliferation $[15,16]$. First, our analysis of the gene expression profiles of TSLP-primed mDCs from RA patients revealed significant upregulation of PD-L1 and much higher expression levels compared with PD-L2. In addition, preliminary data had shown us that PD-L1 was upregulated on SF mDCs of RA patients. Third, data from previous studies [17] and ours indicated overexpression of PD-1 on synovial CD4 T cells of RA patients. Because IL-7 recently was shown to downregulate PD-1 expression on $\mathrm{T}$ cells [18] and because of the potent $\mathrm{T}$ cell stimulatory capacity of IL-7 [19], we also examined the role of IL-7 in the regulation of PD-1/PD-L interactions in hyporesponsiveness of synovial T cells. Our data demonstrate that hyporesponsiveness of synovial CD4 T cells in response to SF-derived CD1c mDCs is dependent on PD-1/PD-L1 interactions and is robustly reversed by IL-7.

\section{Methods}

\section{Patients}

SF was obtained from 13 RA patients during effusion of the knee and $70 \mathrm{ml}$ of heparinized $\mathrm{PB}$ was collected from 16 RA patients. RA was classified according to the American College of Rheumatology criteria [20]. Ethical approval for this study was granted by the medical ethics committee of the University Medical Center Utrecht for the collection of patient samples in compliance with the Helsinki Declaration. All patients gave their written informed consent to participate.

\section{Cell isolation}

Mononuclear cells (MNCs) were isolated from PB and SF by density centrifugation using Ficoll-Paque Plus (GE Healthcare, Uppsala, Sweden). Prior to MNC isolation, PB or SF was diluted 1:1 with RPMI 1640 medium (Gibco/Life Technologies, Grand Island, NY, USA) containing penicillin $(100 \mathrm{U} / \mathrm{ml})$, streptomycin $(100 \mu \mathrm{g} / \mathrm{ml})$ and glutamine $(2 \mathrm{mM})$ (all from PAA Laboratories, Pasching, Austria). PB- and SF-derived CD1c mDCs and CD4 $\mathrm{T}$ cells were isolated from the MNC fraction by magnetic-activated cell sorting (MACS) using CD1c (BDCA-1)-positive dendritic cell and $\mathrm{CD}^{+}{ }^{+} \mathrm{T}$ cell isolation kits (Miltenyi Biotec, Bergisch Gladbach, Germany). $\mathrm{PB}$ memory $\mathrm{T}$ cells were isolated from the CD4 $\mathrm{T}$ cell fraction by their lack of CD45RA expression using the $\mathrm{CD}_{45 \mathrm{RA}^{+}}$isolation kit (Miltenyi Biotec). Isolations were performed according to the manufacturer's instructions.

\section{Cell cultures}

All cells were cultured in RPMI GlutaMAX medium (Gibco/Life Technologies) supplemented with penicillin, streptomycin and 10\% (vol/vol) GemCell human serum AB (Gemini Bio-Products, West Sacramento, CA, USA). The $\mathrm{mDCs}$ were cultured at a cell concentration of $0.5 \times 10^{6}$ cells/ml with or without recombinant TSLP at $20 \mathrm{ng} / \mathrm{ml}$ (R\&D Systems, Minneapolis, MN, USA) for 20 hours in Sarstedt tubes (Sarstedt, Nümbrecht, Germany) at $37^{\circ} \mathrm{C}$.

The functional capacities of PB- and SF-derived mDCs were assessed by measuring activation of autologous CD4 T cells derived from PB and SF. For this purpose, isolated $\mathrm{T}$ cells were seeded in round-bottomed 96-well plates at a concentration of $0.25 \times 10^{6} \mathrm{cells} / \mathrm{ml}$ and kept at $37^{\circ} \mathrm{C}$ in full culture medium before coculturing with the (TSLP-primed) mDCs. Washed TSLP-activated mDCs and unstimulated $\mathrm{mDCs}$ were added to the autologous $\mathrm{T}$ cells (mDC:T cell ratio 1:5 or 1:10) in triplicate in the absence of additional stimuli and cocultured for 6 days. To test the effects of PD-1 blockade or IL-7 effects in cocultures of mDCs and memory T cells from $\mathrm{PB}$ and SF, antiPD-1 mAB ( $1 \mu \mathrm{g} / \mathrm{ml}$; BioLegend, San Diego, CA, USA) or IL-7 (10 ng/ml, PeproTech, Rocky Hill, NJ, USA) was added at the start of the cocultures. Proliferation was measured by $\left[{ }^{3} \mathrm{H}\right]$ thymidine incorporation $(1 \mu \mathrm{Ci} /$ well added during the last 18 hours of a culture period; PerkinElmer, Waltham, MA, USA).

\section{Flow cytometry}

PD-1 expression on CD4 T cells and PD-L1 expression on CD1c mDCs of RA patients were analysed by flow cytometry using a FACSCanto II flow cytometer (BD Biosciences, San Jose, CA, USA). Ex vivo or cultured $\mathrm{mDCs}$ were stained with CD1c phycoerythrin (CD1c-PE; BD Biosciences), CD19 peridinin chlorophyll (CD19-PerCP; BioLegend) and CD274 (PD-L1)-APC (BioLegend). mDCs were gated as 
CD1c-positive and CD19-negative. Ex vivo CD4 T cells were stained with CD45RO fluorescein isothiocyanate (CD45RO-FITC; Dako, Glostrup, Denmark), CD27APC (Invitrogen), CD279 (PD-1)-PE and CD4-PerCP (BioLegend) using isotype antibodies or autofluorescence as controls. All samples were analysed using FlowJo software (TreeStar, Ashland, OR, USA). To compare mean fluorescence intensity (MFI) values, the autofluorescence intensity was subtracted from the MFI of the stains to reveal true expression values.

\section{Real-time quantitative RT-PCR}

To examine TSLP-mediated PD-L1 gene regulation in isolated $\mathrm{CD} 1 \mathrm{c} \mathrm{mDC}$ from $\mathrm{PB}$ and $\mathrm{SF}$ of $\mathrm{RA}$ patients, CD1c mDCs $\left(0.5 \times 10^{6}\right.$ cells $\left./ \mathrm{ml}\right)$ were stimulated with $20 \mathrm{ng} / \mathrm{ml}$ recombinant TSLP (R\&D Systems) or left untreated for 20 hours in Sarstedt tubes at $37^{\circ} \mathrm{C} . \mathrm{mDCs}$ were collected and lysed in Buffer RLT (QIAGEN, Carpinteria, CA, USA) prior to RNA isolation. Total RNA was isolated using the RNeasy Mini Kit (QIAGEN) according to the manufacturer's instructions. RNA quantity was measured by using a NanoDrop spectrophotometer (NanoDrop Technologies, Wilmington, DE, USA), and RNA quality was assessed on a 2100 Bioanalyzer (Agilent Technologies, Santa Clara CA, USA). cDNA synthesis was performed with an automated system (Caliper Life Sciences NV/SA, Teralfene, Belgium), starting with $70 \mathrm{ng}$ of total RNA from each sample, as previously described in detail [21]. Gene expression was quantified by quantitative RTPCR (RT-qPCR) performed in duplicate from $3 \mathrm{ng}$ of CDNA in the presence of SYBR Select Master Mix (Life Technologies, Carlsbad, CA, USA) and $1.5 \mu \mathrm{M}$ of specific primer pairs (PD-L1 forward: 5'-GCT GAA CGC ATT TAC TGT CAC-3', PD-L1 reverse: 5'-TGT TCT TAT CCT CCA TTT CCC A-3'; GAPDH forward: 5'-ATG GGG AAG GTG AAG GTC G-3', GAPDH reverse: 5' GGG GTC ATT GAT GGC AAC AAT A-3'). The analyses were performed using the QuantStudio $12 \mathrm{~K}$ Flex system (Life Technologies) with the following thermal cycle conditions: $95^{\circ} \mathrm{C}$ for 20 seconds, followed by 40 cycles of $95^{\circ} \mathrm{C}$ for 1 second and $60^{\circ} \mathrm{C}$ for 20 seconds. Gene expression values were calculated according to the comparative threshold cycle method [22] using the stably expressed GAPDH as an endogenous control. The value of each control sample was set at 1 and was used to calculate the fold change in target mRNA.

\section{Statistical analysis}

Differences between conditions were assessed by pairedsamples evaluation using the nonparametric Wilcoxon signed-rank test unless indicated otherwise. Unpaired data analysis was performed using the nonparametric Mann-Whitney $U$ test. Data analysis was performed using SPSS software version 20.0 (SPSS, Chicago, IL,
USA). Data were considered statistically significant at $P<0.05$.

\section{Results}

Synovial CD4 T cells from RA patients are hyporesponsive to stimulation by (TSLP-primed) CD1c mDCs

Myeloid DCs derived from SF of RA patients have a strong capacity to activate autologous PB-derived CD4 T cells (Figure 1A) [11]. In addition, TSLP-primed mDCs (TSLP-mDCs) from $\mathrm{PB}$ and SF strongly activate PBderived $\mathrm{T}$ cells (Figure 1A) [13]. Whereas PB-derived CD4 $\mathrm{T}$ cells are strongly activated by TSLP-mDCs (Figures 1A and 1B), SF-derived CD4 T cells were hardly responsive to these in vivo and in vitro activated $\mathrm{mDCs}$ (Figures 1A and 1C).

Several recent observations by others and us indicated that programmed death-1 (PD-1)/PD ligand 1 (PD-L1) interactions could play a role in the regulation of synovial T cell hyporesponsiveness to (TSLP-primed) mDCs from RA patients. First, microarray analysis had shown that PD-L1 mRNA was highly expressed compared with PD-L2 mRNA expression and significantly upregulated upon TSLP activation in addition to upregulated costimulatory and antigen-presenting molecules such as CD80, CD86, HLA class II and CD1c (data not shown). In addition, preliminary data had shown us that PD-L1 was upregulated on SF mDCs of RA patients. Therefore, we set out to investigate the expression levels of PD-1 on T cells, PD-L1 on mDCs from PB and SF of RA patients and the capacity that this interaction has to regulate $\mathrm{T}$ cell responsiveness.

\section{Memory CD4 T cells from synovial fluid express robustly increased PD-1 levels}

CD4 $\mathrm{T}$ cell subsets can be divided into naïve, central memory and effector memory T cells (Tn, Tcm and Tem cells, respectively), based on the expression of CD27 and CD45RO. In RA patients, PB-derived $\mathrm{T}$ cells consist mainly of naïve and central memory $T$ cells, whereas SF-derived $\mathrm{T}$ cells hardly contain any naïve $\mathrm{T}$ cells and consist mainly of central memory and effector memory $\mathrm{T}$ cells (Figure 2A). Because SF memory $\mathrm{T}$ cell hyporesponsiveness upon TSLP-mDC stimulation can be caused by enhanced expression of PD-1 interactions, we measured the expression of this inhibitory receptor on the CD4 T cell subsets derived from PB and SF of RA patients (Figure $2 \mathrm{~B}$, representative histograms). Naïve $\mathrm{T}$ cells from $\mathrm{PB}$ and SF expressed the lowest levels of PD-1, although naïve CD4 T cells from SF had strongly upregulated levels of PD-1 compared with naïve CD4 $\mathrm{T}$ cells from $\mathrm{PB}$ (Figure $2 \mathrm{C}$ ). However, considering the different expression levels of CD45RO on these 'naïve' SF $\mathrm{T}$ cells compared to those from $\mathrm{PB}$, we are reluctant to characterise these cells as 'naïve' (Figure 2A). Mainly 


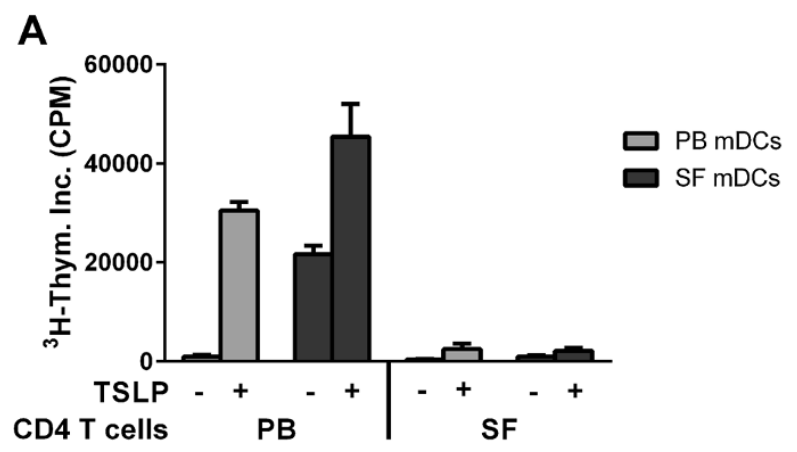

B

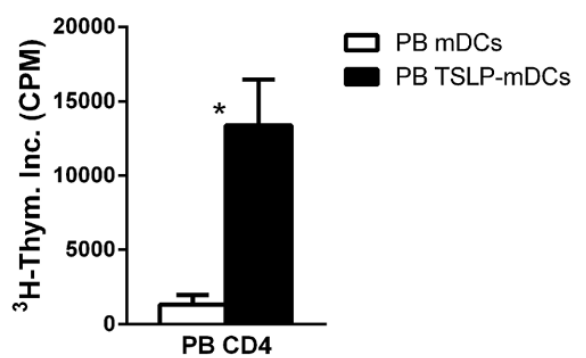

C

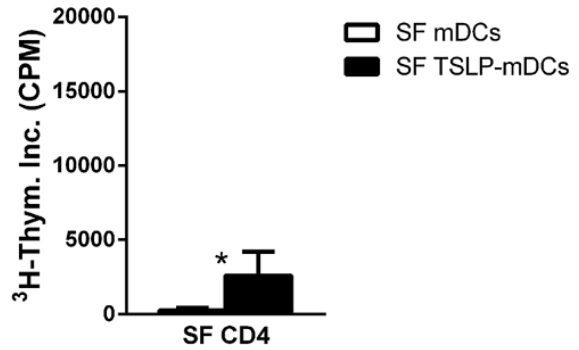

Figure 1 CD4 T cells derived from synovial fluid of rheumatoid arthritis patients are hyporesponsive upon (TSLP-primed) myeloid dendritic cell stimulation in contrast to peripheral blood-derived CD4 T cells. Thymic stromal lymphopoietin (TSLP)-primed myeloid dendritic cells (mDCs) from peripheral blood (PB) as well as both mDCs and TSLP-primed mDCs from synovial fluid (SF) of rheumatoid arthritis (RA) patients strongly activate PB-derived CD4 T cells, whereas SF-derived CD4 T cells are hyporesponsive upon (TSLP-primed) mDC activation. (A) mDC:T cell ratio 1:5, paired analysis of CD4 T cells and mDCs of a representative donor are shown. (B) mDC:T cell ratio 1:10 derived from PB of five RA patients. (C) mDC:T cell ratio 1:10 derived from SF of five RA patients. ${ }^{*} P<0.05$ (statistically significant difference). CPM, counts per minute.

A

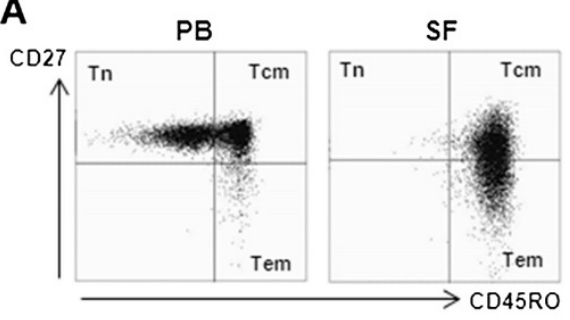

B

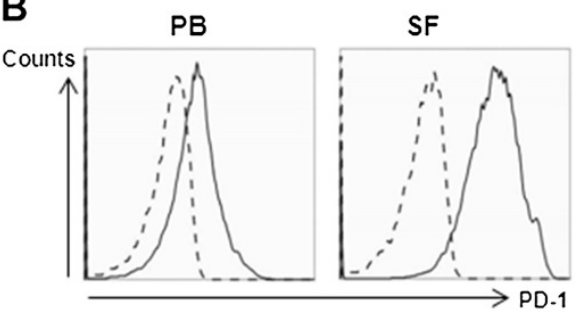

C
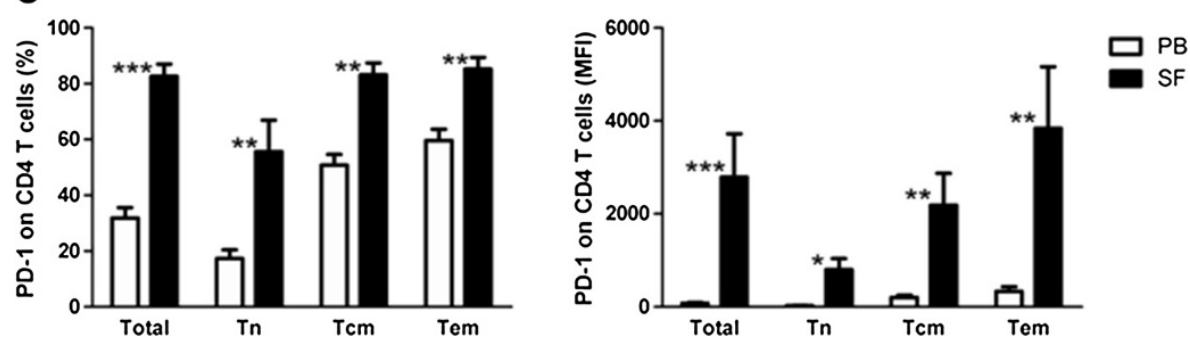

Figure 2 Memory CD4 T cells, in particular synovial fluid-derived T cell subsets, express increased PD-1 levels. (A) CD4 T cells derived from synovial fluid (SF) of rheumatoid arthritis (RA) patients hardly contain any naïve T (Tn) cells and (B) express increased PD-1 levels. Representative histogram of PD-1 expression on PB and SF CD4 T cells of one donor is shown. Dashed line represents autofluorescence. (C) PD-1 expression is increased on central memory $(\mathrm{Tcm})$ and effector memory (Tem) T cells in comparison with naïve T cells (Tn cells) from peripheral blood (PB; $n=9$, both $P<0.01)$ and SF $(n=7$, both $P<0.05)$. PD-1 expression was strongly upregulated on all CD4 T cell subsets derived from SF versus PB of RA patients. ${ }^{*} P<0.05,{ }^{* *} P<0.01$ and ${ }^{* * *} P<0.001$ (statistically significant differences). MFI, mean fluorescence intensity; PD-1, Programmed death 1. 
memory $\mathrm{T}$ cell subsets expressed PD-1, and a robustly increased percentage of $\mathrm{Tcm}$ and Tem cells from SF expressed PD-1 compared with those from PB (Figure 2C).

\section{PD-L1 is upregulated by TSLP and highly expressed on synovial fluid CD1c mDCs}

Confirming microarray data, TSLP significantly upregulated the mRNA expression of PD-L1 in PB- and SF-derived mDCs (Figure 3A), showing much higher expression levels of PD-L1 mRNA expression compared with PD-L2 (data not shown). The PD-L1 mRNA upregulation upon TSLP stimulation of mDCs was confirmed by an increased PD-L1 surface expression (Figure 3B). To confirm our RNA data, we assessed the ex vivo PD-L1 protein expression on CD1c mDCs from $\mathrm{PB}$ and SF of RA patients (Figure $3 \mathrm{C}$ ). The number of $\mathrm{mDCs}$ expressing PD-L1 was significantly increased in SF compared with $\mathrm{PB}$, and $\mathrm{mDCs}$ derived from SF had a higher intensity of PD-L1 expression compared with $\mathrm{mDCs}$ derived from $\mathrm{PB}$ (Figure 3D).

\section{TSLP-mDC driven memory $\mathrm{T}$ cell hyporesponsiveness is} partially dependent on PD-1/PD-L1 interactions

Next, we examined whether the hyporesponsiveness of SF memory CD4 $\mathrm{T}$ cells was caused by their increased expression of PD-1 in combination with the increased PD-L1 expression on SF-derived mDCs. For this purpose, we cocultured memory CD4 $\mathrm{T}$ cells derived from either $\mathrm{PB}$ or SF of RA patients with TSLP-activated $\mathrm{mDC}$ from $\mathrm{PB}$ or $\mathrm{SF}$, respectively, in the presence and absence of PD-1 blocking antibodies. Both memory CD4 $T$ cells from $\mathrm{PB}$ and SF showed a similar reduced capacity to respond to TSLP-activated mDCs (data not shown). Blocking PD-1 interactions in cocultures of memory $\mathrm{T}$ cells activated by $\mathrm{mDC}$ resulted in a significant increase of the $\mathrm{T}$ cell proliferation (Figure 4A). Stimulation of $\mathrm{mDCs}$ by TSLP resulted in upregulated memory $\mathrm{T}$ cell proliferation, which was also elevated by blocking PD-1 ligation (Figure 4A).

Previously, it has been demonstrated that synovial CD4 T cells are hyperresponsive to IL-7 and that IL-7 has the capacity to downregulate PD-1 expression $[18,19]$. Therefore, using another way to regulate PD-1 signalling, we assessed the functional consequence of adding IL-7. IL-7 strongly enhanced memory T cell proliferation activated by mDCs or TSLP-mDCs. However, although we observed that IL-7 inhibited PD-1 expression after 20 hours, PD-1 downregulation was apparently not complete, as IL-7-induced T cell proliferation was further enhanced upon prevention of PD-1 signalling by PD-1-blocking antibodies (Figure 4B).
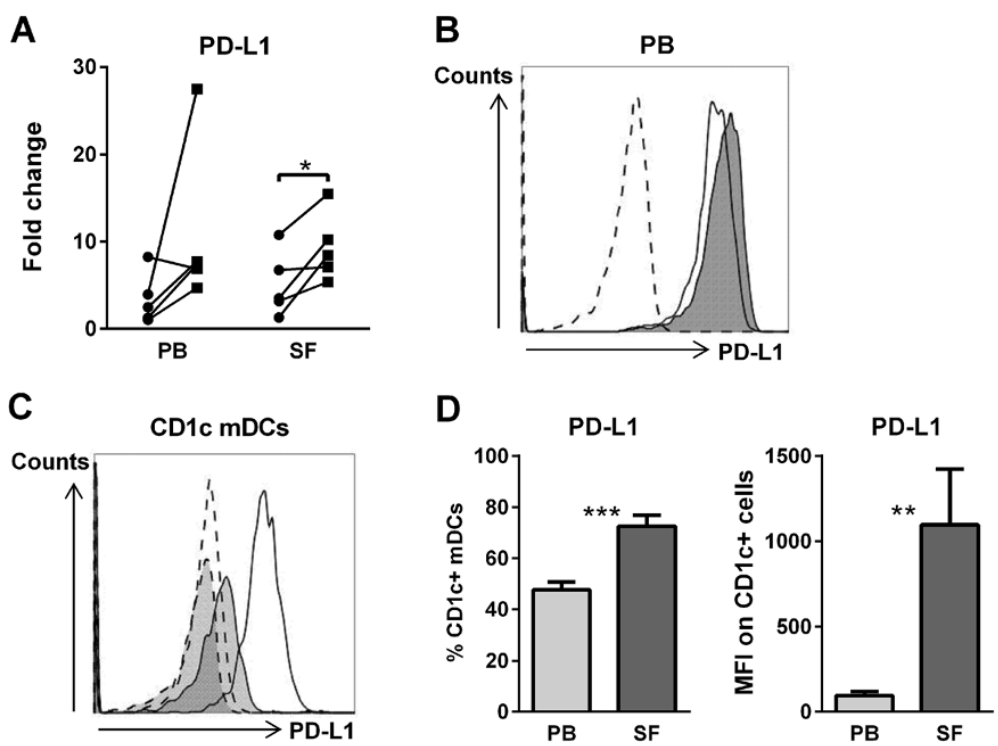

Figure 3 PD-L1 is upregulated by TSLP and highly expressed on synovial CD1c myeloid dendritic cells. (A) Thymic stromal lymphopoietin (TSLP) stimulation of myeloid dendritic cells (mDCs) significantly upregulates PD-L1 mRNA expression (peripheral blood (PB)-derived and synovial fluid (SF)-derived mDCs of rheumatoid arthritis (RA) patients; circles represent unstimulated mDCs, squares represent TSLP-stimulated $m D C s, n=5$ ) and (B) PD-L1 protein expression. Representative histrogram of PD-L1 expression on TSLP-stimulated mDCs (filled dark grey area) and unstimulated mDCs (transparent) from PB of one donor is shown. Dashed line represents autofluorescence. (C, D) PD-L1 is expressed to a higher extent on CD1c mDCs derived from SF $(n=8)$ compared with PB $(n=9)$ of RA patients. (C) Representative histogram of PD-L1 expression on PB mDCs (filled light grey area; solid line) and SF mDCs (transparent area; solid line) of one donor is shown. Dashed line represents autofluorescence for PB mDCs (filled light grey area) and SF mDCs (transparent). (D) Mean percentages and MFI of PD-L1 expression of PB and SF mDCs ( $n=9$ and $n=8$, respectively). ${ }^{*} P<0.05$, ${ }^{* *} P<0.01$, and ${ }^{* * *} P<0.001$ (statistically significant differences). MFI, Mean fluorescence intensity; PD-L1, Programmed death ligand 1. 

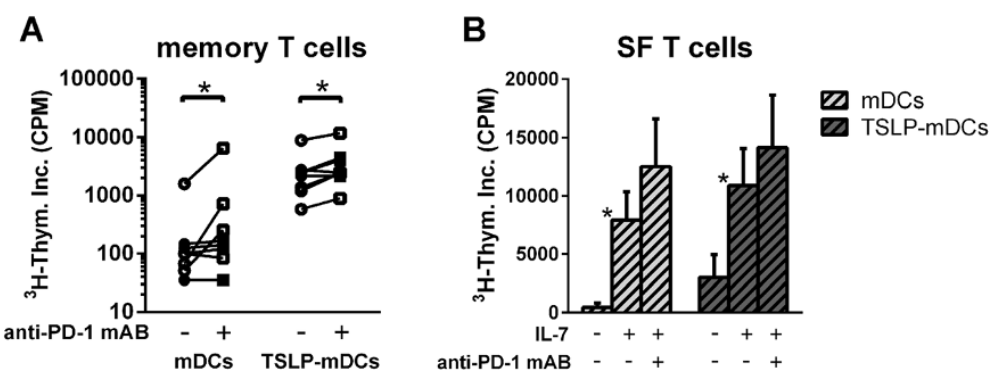

Figure 4 Hyporesponsiveness of memory CD4 T cells from rheumatoid arthritis patients upon TSLP-primed myeloid dendritic cell stimulation is at least partially reversed by PD-1 blockade. (A) Blockade of PD-1/PD-L1 interactions by anti-PD-1 antibody (1 $\mu \mathrm{g} / \mathrm{ml})$ in (TSLP-primed) myeloid dendritic cell (mDC) driven memory CD4 T cell activation from peripheral blood (PB) ( $n=4$, filled symbols) and synovial fluid (SF) ( $n=4$, open symbols) partially restores the T cell proliferative capacity. (B) Memory CD4 T cell hyporesponsiveness from SF ( $n=4)$ is strongly reversed by interleukin-7 (IL-7), a cytokine that largely downregulates PD-1. Additional PD-1 blockade by anti-PD-1 antibody further reversed the downregulated proliferation. Statistical differences between these conditions were assessed using the paired-samples $t$-test. ${ }^{*} P<0.05$ (statistically significant difference). PD-1, Programmed death 1; PD-L1, Programmed death ligand 1; TSLP, Thymic stromal lymphopoietin.

\section{Discussion}

In the present study, we have demonstrated that, in contrast to CD4 T cells from PB, CD4 T cells derived from SF are hyporesponsive upon activation by (TSLPprimed) CD1c mDCs. SF-derived CD4 T cells consist mainly of memory $\mathrm{T}$ cells, which express elevated levels of PD-1, whereas SF-derived CD1c mDCs abundantly express its ligand PD-L1, which is upregulated by TSLP. Memory $\mathrm{T}$ cell hyporesponsiveness is partially dependent on PD-1/PD-L1 interactions because blockade of these interactions by anti-PD-1 antibodies partially restores the $\mathrm{T}$ cell proliferation. Importantly, IL-7, an inhibitor of PD-1 expression, also overcomes hyporesponsiveness and robustly activates synovial memory $\mathrm{T}$ cells in the context of activated (TSLP-primed) mDCs, which could be further enhanced by blocking PD-1.

Similarly to TSLP-primed mDCs from PB, SF-derived mDCs have a strongly enhanced capacity to activate $\mathrm{T}$ cells derived from $\mathrm{PB}$ that is even upregulated upon TSLP stimulation [13]. Associated with this enhanced T cell stimulatory capacity, enhanced expression of antigen-presenting molecules, including CD1c and HLA class II, and costimulatory molecules, including CD80, CD86 and CD40, have been demonstrated [11,13]. In support of this finding, activation of $\mathrm{PB}$-derived $\mathrm{T}$ cells by (TSLP-primed) mDCs is strongly dependent on costimulation and antigen presentation as blockade of HLAclass II molecules or CD80/86 costimulation blocked T cell activation [13]. However, despite the abundance of antigen-presenting and costimulatory molecules, the activity of T cells derived from SF of RA patients activated by autologous (TSLP-primed) mDCs is strongly hampered. Although several mechanisms might be involved in the reduced capacity of SF-derived T cells in response to activated $\mathrm{mDCs}$, the role of PD-1/PD-L1 interactions, which negatively regulate $\mathrm{T}$ cell activation [15], was investigated for obvious reasons, such as overexpression of
PD-L1 by activated mDCs from SF and high PD-L1 mRNA levels induced by TSLP. Blockade of PD-1/PD$\mathrm{L} 1$ interactions has been shown to result in increased $\mathrm{T}$ cell activity [23] and PD-1 deficiency, and PD-L1 deficiency is shown to play a critical role in the development of autoimmune disorders in mice [24,25].

In line with our results showing increased PD-1 expression on SF-derived memory $\mathrm{T}$ cells compared with PB-derived T cells, PD-1 expression was previously described to be increased on SF-derived CD4 T cells [17]. These SF-derived $\mathrm{T}$ cells were previously suggested to be resistant to PD-1 mediated suppression, as PD-L1 expression on SF-derived CD14+ monocytes and macrophages was not sufficiently high to effectively downregulate $\mathrm{T}$ cell activation [17]. In contrast to this latter suggestion, we observed hyporesponsiveness of SF $\mathrm{T}$ cells upon activation by in vivo activated synovial mDCs and in vitro activated TSLP-mDCs, which, in contrast, expressed high levels of PD-L1. PD-1-blocking antibodies, blocking interactions with PD-L1, resulted in an increase in the $\mathrm{T}$ cell proliferation, indicating that SFderived $\mathrm{T}$ cell hyporesponsiveness is at least partially dependent on PD-1/PD-L interactions. However, based on the strong expression of both PD-1 on $\mathrm{T}$ cells and PD-L1 on activated $\mathrm{mDCs}$, more robust reversal of $\mathrm{T}$ cell hyporesponsiveness was expected. The lack of response might be due to the fact that PD-1 is also expressed on regulatory $\mathrm{T}$ cells, preventing immunosuppression by these cells [26]. Because previous studies, including those of our group, have demonstrated an increased presence of regulatory $\mathrm{T}$ cells in the SF [27], blockade of PD-1, next to increased activation of effector cells, might enhance the function of regulatory $\mathrm{T}$ cells, resulting in a somewhat more limited reversal of $\mathrm{T}$ cell inhibition. An alternative explanation is that enhanced antigen presentation due to robust upregulation of HLA class II by TSLP may limit the effect of PD-1 blockade, 
which is consistent with previous data demonstrating that the inhibitory effect of the PD-1/PD-L pathway on CD4 T cells was greatest at lower antigen concentrations $[16,25]$. Additionally, blockade of PD-L1 has been shown to more potently restore $\mathrm{T}$ cell proliferation compared with PD-1 blockade in antigen-driven $\mathrm{T}$ cell responses [28]. Although not tested in the present study, this might result in a stronger restoration of the SF-derived T cell hyporesponsiveness.

Hyporesponsiveness of SF-derived CD4 T cells upon $\mathrm{mDC}$ or TSLP-mDC stimulation was robustly reversed by IL-7, which is in line with previous data demonstrating vigorous activation and even hyperresponsiveness of synovial CD4 T cells in the context of monocytic cells [19]. Recently, IL-7 was shown to prevent shutdown of $\mathrm{T}$ cell activation by downregulation of PD-1 expression [18]. We also found PD-1 downregulation upon IL-7 stimulation of CD4 T cells in the present study (data not shown). Apart from the capacity of IL-7 to downregulate PD-1 expression [18], IL-7 is also shown to overcome PD-1-mediated inhibition of T cells by STAT5 activation that is regulated by IL-2 and family members such as IL7 and IL-15 [29,30]. IL-7 and IL-15 are both abundantly present in joints of RA patients [19,31], which suggests that the inflammatory environment in RA joints could play a critical role in overcoming PD-1-mediated inhibition of $\mathrm{T}$ cells. Although reversing PD-1-mediated inhibition is likely a crucial mechanism whereby IL-7 overcomes hyporesponsiveness, other mechanisms induced by IL-7 could be involved as well, such as upregulation of (co)stimulatory molecules that were previously found to be induced by IL-7, both on T cells (for example, lymphocyte function-associated antigen and CD69) and on myeloid cells (CD40, CD80, CD86) [19].

\section{Conclusions}

The present study demonstrates that PD-1/PD-L1 interactions between SF-derived $\mathrm{T}$ cells and in vivo activated SF $\mathrm{mDCs}$ or in vitro TSLP-primed mDCs contribute to T cell hyporesponsiveness. The potential of IL-7 to robustly counteract this hyporesponsiveness suggests that such cytokines in joints of RA patients might strongly contribute to the activation of memory $\mathrm{T}$ cells, in addition to the potential of SF-derived $\mathrm{mDCs}$ to activate autologous peripheral (naïve) CD4 T cells attracted to the joint.

\footnotetext{
Abbreviations

BDCA: Blood-derived dendritic cell antigen; DC: Dendritic cell; FACS: Fluorescence-activated cell sorting; IL: Interleukin; mDC: Myeloid dendritic cell; MNC: Mononuclear cell; PB: Peripheral blood; PD-1: Programmed death 1; PD-L: Programmed death ligand; RA: Rheumatoid arthritis; RT-qPCR: Quantitative reverse transcription polymerase chain reaction; SF: Synovial fluid; Tcm: Central memory T cell; Tem: Effector memory T cell; Tn: Naïve T cell; TSLP: Thymic stromal lymphopoietin.
}

\section{Competing interests}

The authors declare that they have no competing interests.

\section{Authors' contributions}

FMM participated in the study design, acquisition of data, analysis and interpretation of data, and manuscript drafting. KMGWJ contributed to the acquisition of data and critical revision of the manuscript. JWJB and FPJGL contributed to the study design, interpretation of data and critically revision of the manuscript. JAGR contributed to the study design, analysis and interpretation of data, and manuscript drafting. All authors read and approved the final manuscript.

\section{Acknowledgements}

This research was performed within the framework of the Center for Translational Molecular Medicine (www.ctmm.nl) and the Dutch Arthritis Foundation project TRACER (grant 04I-202).

Received: 14 March 2014 Accepted: 18 November 2014

Published online: 30 November 2014

\section{References}

1. Feldmann M, Brennan FM, Maini RN: Rheumatoid arthritis. Cell 1996, 85:307-310.

2. Morita Y, Yamamura M, Kawashima M, Harada S, Tsuji K, Shibuya K, Maruyama K, Makino H: Flow cytometric single-cell analysis of cytokine production by CD4+ T cells in synovial tissue and peripheral blood from patients with rheumatoid arthritis. Arthritis Rheum 1998, 41:1669-1676.

3. van Roon JA, van Roy JL, Duits A, Lafeber FP, Bijlsma JW: Proinflammatory cytokine production and cartilage damage due to rheumatoid synovial T helper-1 activation is inhibited by interleukin-4. Ann Rheum Dis 1995, 54:836-840.

4. Cornelissen F, van Hamburg JP, Lubberts E: The IL-12/IL-23 axis and its role in Th17 cell development, pathology and plasticity in arthritis. Curr Opin Investig Drugs 2009, 10:452-462.

5. Chabaud M, Durand JM, Buchs N, Fossiez F, Page G, Frappart L, Miossec P: Human interleukin-17: a T cell-derived proinflammatory cytokine produced by the rheumatoid synovium. Arthritis Rheum 1999, 42:963-970.

6. Thomas R, Davis LS, Lipsky PE: Rheumatoid synovium is enriched in mature antigen-presenting dendritic cells. J Immunol 1994, 152:2613-2623.

7. Merad M, Sathe P, Helft J, Miller J, Mortha A: The dendritic cell lineage: ontogeny and function of dendritic cells and their subsets in the steady state and the inflamed setting. Annu Rev Immunol 2013, 31:563-604.

8. Satpathy AT, Wu X, Albring JC, Murphy KM: Re(de)fining the dendritic cell lineage. Nat Immunol 2012, 13:1145-1154.

9. Ziegler-Heitbrock L, Ancuta P, Crowe S, Dalod M, Grau V, Hart DN, Leenen PJ, Liu YJ, MacPherson G, Randolph GJ, Scherberich J, Schmitz J, Shortman K, Sozzani S, Strobl H, Zembala M, Austyn JM, Lutz MB: Nomenclature of monocytes and dendritic cells in blood. Blood 2010, 116:e74-e80.

10. Dzionek A, Fuchs A, Schmidt P, Cremer S, Zysk M, Miltenyi S, Buck DW, Schmitz J: BDCA-2, BDCA-3, and BDCA-4: three markers for distinct subsets of dendritic cells in human peripheral blood. J Immunol 2000, 165:6037-6046.

11. Moret FM, Hack CE, van der Wurff-Jacobs KM, de Jager W, Radstake TR, Lafeber FP, van Roon JA: Intra-articular CD1c-expressing myeloid dendritic cells from rheumatoid arthritis patients express a unique set of $T$ cell-attracting chemokines and spontaneously induce Th1, Th17 and Th2 cell activity. Arthritis Res Ther 2013, 15:R155.

12. Koyama K, Ozawa T, Hatsushika K, Ando T, Takano S, Wako M, Suenaga F, Ohnuma Y, Ohba T, Katoh R, Sugiyama H, Hamada Y, Ogawa H, Okumura K, Nakao A: A possible role for TSLP in inflammatory arthritis. Biochem Biophys Res Commun 2007, 357:99-104.

13. Moret FM, Hack CE, van der Wurff-Jacobs KM, Radstake TRDJ, Lafeber FPJG, van Roon JAG: Thymic stromal lymphopoietin, a novel proinflammatory mediator in rheumatoid arthritis that potently activates CD1c+ myeloid dendritic cells to attract and stimulate T cells. Arthritis Rheum 2014, 66:1176-1184.

14. Hartgring SA, Willis CR, Dean CE Jr, Broere F, van Eden W, Bijlsma JW, Lafeber FP, van Roon JA: Critical proinflammatory role of thymic stromal lymphopoietin and its receptor in experimental autoimmune arthritis. Arthritis Rheum 2011, 63:1878-1887.

15. Freeman GJ, Long AJ, Iwai $Y$, Bourque $K$, Chernova T, Nishimura $H$, Fitz $\sqcup$, Malenkovich N, Okazaki T, Byrne MC, Horton HF, Fouser L, Carter L, Ling V, Bowman MR, Carreno BM, Collins M, Wood CR, Honjo T: Engagement of the PD-1 immunoinhibitory receptor by a novel B7 family member leads to negative regulation of lymphocyte activation. J Exp Med 2000, 192:1027-1034. 
16. Latchman Y, Wood CR, Chernova T, Chaudhary D, Borde M, Chernova I, Iwai Y, Long AJ, Brown JA, Nunes R, Greenfield EA, Bourque K, Boussiotis VA, Carter LL, Carreno BM, Malenkovich N, Nishimura H, Okazaki T, Honjo T, Sharpe AH, Freeman GJ: PD-L2 is a second ligand for PD-1 and inhibits T cell activation. Nat Immunol 2001, 2:261-268.

17. Raptopoulou AP, Bertsias G, Makrygiannakis D, Verginis P, Kritikos I, Tzardi M, Klareskog L, Catrina Al, Sidiropoulos P, Boumpas DT: The programmed death 1 /programmed death ligand 1 inhibitory pathway is up-regulated in rheumatoid synovium and regulates peripheral $\mathrm{T}$ cell responses in human and murine arthritis. Arthritis Rheum 2010, 62:1870-1880.

18. Penaranda C, Kuswanto W, Hofmann J, Kenefeck R, Narendran P, Walker LS, Bluestone JA, Abbas AK, Dooms H: IL-7 receptor blockade reverses autoimmune diabetes by promoting inhibition of effector/memory T cells. Proc Natl Acad Sci U S A 2012, 109:12668-12673.

19. van Roon JA, Verweij MC, Wijk MW, Jacobs KM, Bijlsma JW, Lafeber FP. Increased intraarticular interleukin-7 in rheumatoid arthritis patients stimulates cell contact-dependent activation of $\mathrm{CD}^{+} \mathrm{T}$ cells and macrophages. Arthritis Rheum 2005, 52:1700-1710.

20. Arnett FC, Edworthy SM, Bloch DA, McShane DJ, Fries JF, Cooper NS, Healey LA, Kaplan SR, Liang MH, Luthra HS, Medsger TA Jr, Mitchell DM, Neustadt DH, Pinals RS, Schaller JG, Sharp JT, Wilder RL, Hunder GG: The American Rheumatism Association 1987 revised criteria for the classification of rheumatoid arthritis. Arthritis Rheum 1988, 31:315-324.

21. Roepman P, Wessels LF, Kettelarij N, Kemmeren P, Miles AJ, Lijnzaad P, Tilanus MG, Koole R, Hordijk GJ, van der Vliet PC, Reinders MJ, Slootweg PJ Holstege FC: An expression profile for diagnosis of lymph node metastases from primary head and neck squamous cell carcinomas. Nat Genet 2005, 37:182-186.

22. Livak K, Schmittgen TD: Analysis of relative gene expression data using real-time quantitative PCR and the $2_{T}^{-\Delta \Delta C}$ method. Methods 2001, 25:402-408,

23. Brown JA, Dorfman DM, Ma FR, Sullivan EL, Munoz O, Wood CR, Greenfield EA Freeman GJ: Blockade of programmed death-1 ligands on dendritic cells enhances T cell activation and cytokine production. J Immunol 2003, 170:1257-1266

24. Ansari MJ, Salama AD, Chitnis T, Smith RN, Yagita H, Akiba H, Yamazaki T, Azuma M, Iwai H, Khoury SJ, Auchincloss H Jr, Sayegh MH: The programmed death-1 (PD-1) pathway regulates autoimmune diabetes in nonobese diabetic (NOD) mice. J Exp Med 2003, 198:63-69.

25. Latchman YE, Liang SC, Wu Y, Chernova T, Sobel RA, Klemm M, Kuchroo VK, Freeman GJ, Sharpe AH: PD-L1-deficient mice show that PD-L1 on T cells, antigen-presenting cells, and host tissues negatively regulates $\mathrm{T}$ cells. Proc Natl Acad Sci U S A 2004, 101:10691-10696.

26. Sage PT, Francisco LM, Carman CV, Sharpe AH: The receptor PD-1 controls follicular regulatory T cells in the lymph nodes and blood. Nat Immunol 2013, 14:152-161.

27. Walter GJ, Evans HG, Menon B, Gullick NJ, Kirkham BW, Cope AP, Geissmann F, Taams LS: Interaction with activated monocytes enhances cytokine expression and suppressive activity of human CD4+D45ro+CD25+CD127 low regulatory T cells. Arthritis Rheum 2013, 65:627-638.

28. Rosignoli G, Lim CH, Bower M, Gotch F, Imami N: Programmed death (PD)-1 molecule and its ligand PD-L1 distribution among memory CD4 and CD8 T cell subsets in human immunodeficiency virus-1-infected individuals. Clin Exp Immunol 2009, 157:90-97.

29. Bennett F, Luxenberg D, Ling V, Wang IM, Marquette K, Lowe D, Khan N, Veldman G, Jacobs KA, Valge-Archer VE, Collins M, Carreno BM: Program death-1 engagement upon TCR activation has distinct effects on costimulation and cytokine-driven proliferation: attenuation of ICOS, IL-4, and IL-21, but not CD28, IL-7, and IL-15 responses. J Immunol 2003, 170:711-718.

30. Leonard WJ, Lin JX: Cytokine receptor signaling pathways. J Allergy Clin Immunol 2000, 105:877-888.

31. Mclnnes IB, Al-Mughales J, Field M, Leung BP, Huang FP, Dixon R, Sturrock RD, Wilkinson PC, Liew FY: The role of interleukin-15 in T-cell migration and activation in rheumatoid arthritis. Nat Med 1996, 2:175-182.

doi:10.1186/s13075-014-0497-x

Cite this article as: Moret et al.: Synovial T cell hyporesponsiveness to myeloid dendritic cells is reversed by preventing PD-1/PD-L1 interactions. Arthritis Research \& Therapy 2014 16:497.

\section{Submit your next manuscript to BioMed Central and take full advantage of:}

- Convenient online submission

- Thorough peer review

- No space constraints or color figure charges

- Immediate publication on acceptance

- Inclusion in PubMed, CAS, Scopus and Google Scholar

- Research which is freely available for redistribution 